\section{A CASE OF HAIR BALL IN THE STOMACH*}

\section{J. B. HARVIE, M.D.}

$\Delta$ ttending Surgeon at Troy and Samaritan Hospitals and Consult. ing Surgeon, Leonard Hospital. TROY, N.Y.

The following case is interesting on account of its comparative rarity and on account of the fact that a mass completely filling the entire stomach, and causing distension much beyond its normal capacity, could exist for years, creating no gastric disturbances.

Patient.-M. H., female under 10 years of age; of North Adams, Mass,,was sent by Dr. E. E. Russel. She was a seven months infant and weighed 3 pounds at birth. The child was removed instrumentally on account of puerperal convulsions in mother and was breast fed.

Bistory.-Whooping cough and measles, at eighth year; both light attacks. Always a moderately nervous child. A squint of left eye was corrected by glasses. No convulsions. Always a good sleeper. Appetite good; food well digested and patient well nourished. School attendance began between six and seven years of age, was bright in her studies, active on her feet, always ready for her meals and never complained of any

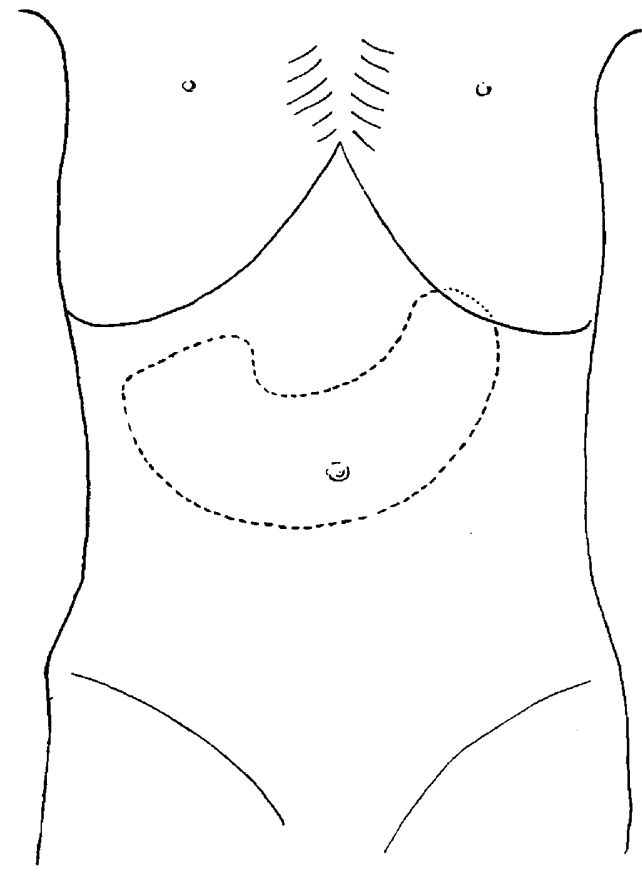

Fig. 1.-Dlagram showing relative position of stomach.

discomfort in the abdomen. She began picking at carpets and woolly materials and swallowing the pieces when she was a very young child-before she commenced to walk. She developed an early desire to pick her hair and swallow it; she was almost completely bald from this habit, and her mother noticed small masses of hair in her stools at odd times for many years. The history of the case during her entire life time until the illness immediately preceding operation was absolutely uneventful.

Present Illness.-She was taken ill May 14, 1907, with nausea and more or less vomiting. Pain in the epigastrium followed the vomiting which was so severe that Dr. E. E. Russel, the family physician, was sent for. He found a mass in the upper abdomen, sausage shaped, which he thought might be impacted feces. A brisk cathartic and high enema was followed by a copious. purge which contained a small bundle of hair. At his next visit the mass was even more distinct and answered in every detail the outline of the stomach. This, taken with the past habits of the child, and the fact that masses of hair had appeared in the movements from time to

- Read before the Third District Branch, New York State Medical Society, Albany, N. Y. time, led him to make a diagnosis of a probable hair ball in the stomach.

Examination.Examination at Troy Hospital, May 20, 1907, showed a well nourished child of go : musculature; well developed and full blooded. The heart and lungs were both normal. Pulse rate was not accelerated and there was no increased temperature. On inspection a well defined mass was seen in the epigastrium, corresponding to the outline of the stomach, somewhat movable on inspiration and expiration. On palpation the mass had rather a doughy feel and an indistinct fine crackling was elicited. There was moderate gastroptosis. The stomach extended in its long axis from the outer border of the left rectus muscle at its costal attachment to well beyond the outer side of the right rectus, with its most dependent part somewhat below the level of the umbilicus (Fig. 1). The shape and outline approached very nearly a semi-circle. The introduction of a stomach tube was accomplished without difficulty until it was blocked by the tumor, at the cardiac end of the stomach. With some coaxing it passed along sufficiently to introduce a few ounces of fluid, and by continued repeating and syphoning off, sixteen ounces were introduced at one time. The fluid returned clear but contained a moderate amount of mucus. This was repeated several times before operation. With the introduction of the fluid the stomach became more prominent. Under anesthesia the tumor was easily movable and its entire outline readily demonstrated. The fine crackling (similar to rolling a bundle of hair between the fingers) was evident and strongly corroborative of the composition of the mass.

Operation.-An incision was made through the right rectus muscle, splitting its sheath anteriorly and posteriorly. The

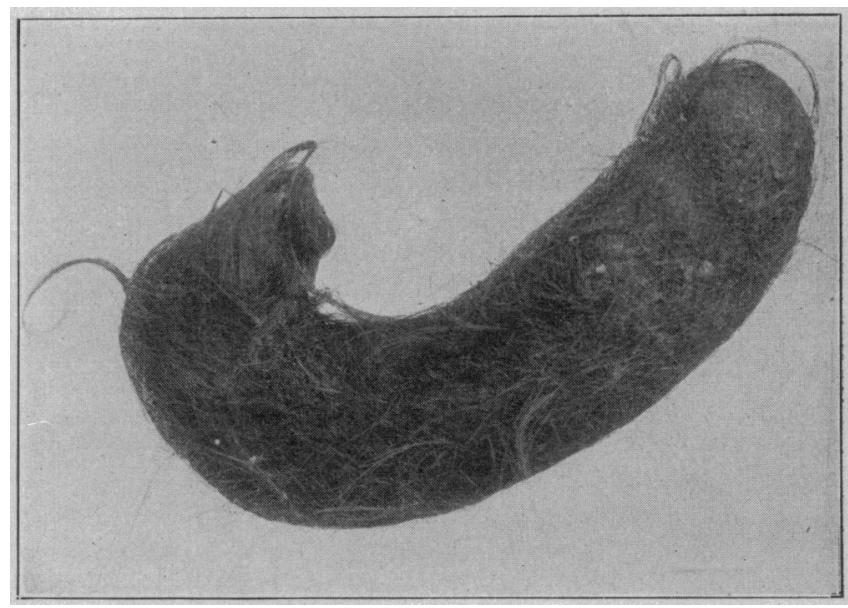

Fig. 2.-The hair tumor removed from stomach; $1 / 3$ size.

cardiac end of the tumor was presented in the line of incision and after walling off the cavity thoroughly an incision in the anterior wall of the stomach sufficient to permit of the engagement of the masss its delivery was readily affected. It proved to be a bundle of hair as diagnosticated, was a perfect mold of the stomach-extending in its long axis from the cardiac orifice through the pylorus into the upper part of the duodenum. The pyloric end was conical and projected into the duodenum about $11 / 4$ inches. The hair ball, from its peculiar shape, (its great curvature measuring 13 inches and its circumference 7 inches) caused more elongation than dilatation of the stomach. It was made up of hair of varying lengths, absolutely black, and densely packed (Fig. 2).

The gastric mucosa was highly irritated, but there were no definite areas of ulceration. The incision was closed by means of mattress sutures of fine silk, and the abdomen closed without drainage.

The patient was discharged from this hospital on the twelfth day after operation completely recovered.

It has been known for a long time that concretions may develop within the stomach, giving rise to an abdominal tumor. These concretions are made up of 
articles swallowed, either intentionally or otherwise, from force of habit, hysterical individuals or those who are mentally disturbed. Those masses are usually made up of hair, woolly materials or vegetable fiber, string, and sometimes resinous material. The hair ball, on account of the habit of swallowing the hair in small amounts, together with the continuation of the habit, eventuates in the formation of a well-defined tumor. Before the ball attains any considerable size it is usually oval in shape and will be found located near the pyloric orifice. With increase in volume the movements of the stomach will gradually alter the outline until it assumes a contour corresponding exactly to the outline of the stomach itself, or, in other words, constituting a true mold of the stomach.

Where a large accumulation is found it may extend, as in this case, from the cardiac orifice through the pylorus well into the duodenum. From the constant action of the gastric walls the bundle of hair becomes rolled into an exceedingly solid mass and may possess enormous proportions, if made up purely of hair or vegetable fiber, before giving rise to disturbances of a serious kind. Those accumulations are found in the lower animals. They are exceedingly common in horses, cattle, dogs and angora cats principally, and are said to cause death occasionally. The reported cases have occurred almost entirely in females. Of the twenty cases of hair ball in the stomach which have been reported, all but one occurred in females.

The ${ }^{1}$ first case reported in the literature, by M. Baudamant, in 1779 , was a male, who died at the age of 16 years. At the autopsy a hair tumor was found in the stomach $17 \mathrm{~cm}$. in length, and one $12 \mathrm{~cm}$. in length in the duodenum.

The cases reported would seem to substantiate the fact that the habit of hair swallowing is acquired at an early age, and although the tendency to engage in such practice is greater when the hair is long, and worn loose, hanging about the shoulders, nevertheless, the habit has been noted in some instances in creeping children.

RUSSEL'S CASE." - History.-Woman, aged 31, had a large tumor in the abdomen, which was supposed to be an enlargement of the spleen. It occupied the left side of the abdomen and extended into the pelvis. It presented a concavity on its inner side and passed beneath the false ribs. The entire splenic region was dull on percussion. Its great length in proportion to its breadth caused some doubt as to its being splenic. It had been increasing in size for 17 years. It was first observed when the patient was 14 . The patient's health had been good and she suffered little from indigestion. She had vomited blood however. Death in this case followed a miscarriage.

Autopsy.-The autopsy was made by Dr. Prusser. The tumor consisted of a mass of hair molded to the shape of the stomach and was presented in situ. It had drawn down the stomach in a vertical line, so that the pylorus lay in the pelvis. The mass was divided into two unequal parts fitied to one another, constituting a hard and solid mass of hair. It weighed 4 pounds and 7 ounces. In this case the patient was not emotional nor hysterical and the habit of hair swallowing was not suspected. This woman had no difficulty in swallowing her food.

INMAN's CASE.-T. Inman ${ }^{8}$ reports a case occurring in the practice of Dr. Dickinson of Liverpool.

History.-Woman, aged 34, died with obscure symptoms. The stomach was found full of hair matted into a mass of the shape and size of the viscus when distended by a full meal. Specimen

1. Jour. de Méd., 1779 .

2. Med. Times and Gaz., June 26, 1869.

3. Med. Times and Gaz., July 3, 1869 . in the Museum of Royal Infirmary Medical School. The patient had been in the habit of swallowing hair.

BesT's s $^{4}$ CASE.-History.-Female, aged 30 , began to have pain in her stomach when she was 15 years old, with vomiting and diarrhea. She was constantly under the care of a physician. A tumor was discovered in January, 1863, and was supposed to be a scirrhus cancer of the stomach. Best was much puzzled at the case and treated it as one of fecal impaction. In September, 1869, while the patient was working in the field, she had a violent pain in the abdomen, followed by peritonitis, with renewed attacks, when death occurred in October of that year.

Autopsy.-This disclosed a general peritonitis. The peritoneal cavity contained 10 ounces of dark fluid. The stomach was completely filled with a hair ball, which weighed 35 ounces. The stomach was perforated. There was a single round ulcer at the seat of perforation on the posterior gastric wall. In this case the patient's relatives bore witness to the fact that this woman had made a practice of eating her hair for 15 years.

BERG'S ${ }^{5}$ CASE.-History-Female, aged 26 , had been suffering with dyspepsia and vomiting for 3 years. A tumor had been noticed in the epigastrium for 2 years, with very rapid growth in the last six months. Entered hospital (Stockholm) May 3I, 1887.

Operation.-The stomach was opened by incision $8 \mathrm{~cm}$. in length, parallel to the greater curvature. A tumor of hair was found which weighed $900 \mathrm{gm}$. The patient made an excellent recovery. The mother said that when the child was 3 years old she had the habit of chewing her hair.

Boellingen's ${ }^{\circ}$ Case.-History.-Girl, aged 16 , had been complaining for $2 \frac{1}{2}$ years with symptoms of gastrointestinal catarrh, loss of appetite, vomiting, abdominal pain, liquid movements, insomnia, and finally no nourishment except liquid could be taken. A tumor was detected in the epigastrium. Death resulted from exhaustion.

Autopsy.-Stomach and duodenum distended with a great amount of hair. As a child she had been in the habit of pulling out hair putting it in her mouth, which she must have swallowed.

JACOBSON's CASE. - History.-Child aged 11, complained for 2 years and 6 months of gastric disturbance; vomited a great deal of frothy mucus but never any food or blood. There was a swelling noticed in her abdomen one year prior to the operation. She suffered with colicky pains, particularly at night. She was compelled to live on milk, solid food causing severe dis. tress. The child was poorly developed. A successful gastrostomy was done.

Charles Stover, Amsterdam, N. Y., reported at Amsterdam Jity Medical Society, 1895, the following case:

History.-Girl, aged 11, presented symptoms of incomplete obstruction for a period of ten days, with rectal tenesmus. It was said she had suffered with colicky pains in the upper abdomen for two years. She was in the habit of eating her hair, the temporal regions being bald. Examination of the anus showed a projecting tuft of hair like a camel's hair brush. An enema was followed by the discharge of a ball of hair and relief of all the symptoms. The mass measured two inches in length and three inches in circumference.

The first successful case was reported by Schoenborn ${ }^{8}$ in 1883. J. Knowsley Thornton, ${ }^{\circ}$ Jan. 9, 1886, reports a case in which a hair ball weighing $2 \mathrm{lb}$. was successfully removed in 1884 . In Thornton's case the diagnosis of hair ball in the stomach was made prior to operation. The diagnosis based on the fact that the patient had passed small quantities of hair in the movements. This is the first authentic case in which the character of the mass was diagnosticated prior to exploration.

4. British Med. Jour., Dec. 11, 1869.

5. Sajous' Ann. Universal Med. Sciences, 1889,

6. Münch. med. Wochschr., June 2, 1891

7. Med. News, 1901

8. Langenbuch's Arch. 1. klin. Chir., 1883

9. Lancet, Jan. 9, 1886, also Trans. Path. Soc., London, 1886. 
William Finder ${ }^{10}$ reported a case occurring in the practice of the late William S. Cooper.

History.-The patient was suffering great pain, intensified on the slightest movement. She was much emaciated; abdominal walls exceedingly thin. A tumor was distinctly seen and felt in the upper adomen. On palpation the mass was hard. Was unable to take nourishment, and there were constant unsuccessful efforts at vomiting. The ciiagnosis of probable cancer was made and she died 10 or 12 days after this examination from exhaustion.

Autopsy.-An autopsy was made 40 hours after death and two masses of hair were found in the stomach, the combined weight being 16 ounces. There were two deep ulcers in the stomach which were nearly perforated. The specimens are now in the Pathologic Museum of the College of Physicians and Surgeons, New York.

It would seem, so far as I can learn, that in only two of the cases was the identity of the tumor properly recognized before operation: 1 , J. Knowsley Thornton's, in whose patient hair was found in the evacuations, and together with the previous habits of the patient, led up to a correct diagnosis: 2, Stelzner ${ }^{11}$ gives the credit for a correct diagnosis to his knowledge of Schöenborn's case In the other cases the diagnosis was cleared up on the operating table or postmortem.

The differentiation between a foreign body of this nature in the stomach and malignant disease should not be particularly difficult if one would take the trouble to ascertain a careful history. The early age at which this occurs; the slow growth of the tumor; the good health of the patient, independent of a mass which can be seen and felt; the absence of pain in manipulation and its physical characteristics are usually sufficient to settle the question. Femick of London reports a case in which very obstinate dyspepsia occurred in a young lady who was bald on both sides of her head from constant pulling and swallowing of her hair. Cessation of the practice was followed by gradual improvement. He suggests the importance of careful inquiry regarding the habits and occupation of young adults whenever a painless tumor is found in the stomach or intestines, and to bear in mind the possibility of a concretion. The tendency to evade questions and throw one off the track regarding the vicious habits must be carefully borne in mind. ${ }^{\mathbf{2}}$

\footnotetext{
10. Trans. New York State Med. Assn., 1886.

11. Centrbl. f. Chir., 1896, xxx1.

12. The following are additional references to halr tumors:

d'Hautville (M.): Jour. Méd. Chlr., Paris, 1813. Halr tumor cound at autopsy.

Ritchle: Edin. Monthly Jour., 1849, 1x. Female, aged 21 ; hair tumor found at autopsy ; weight, 21 oz.

Pollock: Proc. Path. Soc., London, 1852. Girl died at 18 ; halr mass found in stomach and duodenum.

May, Jr., (G.) : Trans. Chir. Soc., London, 1855. Hair tumor found at autopsy.

Gull (W.) : Trans. Chlr. Soc., London, 1871.

Swain : Lancet, April, 1895. Successful gastrostomy : diagnosis cleared up at operation.

Schulten: Centrbl. 1. Chlr., 1896, [11. Successfu] gastrostomy; diagnosis made at operation.

Allen (W. L.) : THy Journal A. M. A., Feb. 15, 1896. Exploratory laparotomy; hair ball successfully removed.

Schopf: Wien. med. Bl., 1900, also Med. Record. April 21, 1900. Successful operation, at which time diagnosis was made.
}

Scrofulodermata.-N. E. Aronstam, in Central States Medical Monitor, states that scrofulodermata are very difficult o cure. It would seem that au times a cure may be apparently effected, when it breaks out again in renewed vehemence. Especially is this the case in scrofulous or tuberculous glands of the neck. If external applications and the internal administration of cod-liver oil and iron iodid does not avail, we must have recourse to curettement of the glands with subsequent cauterization. Their total extirpation should not be attempted, for fear of dissemination of the tuberculous process constitutionally and the subsequent infection of more vital organs.
POLIOENCEPHALITIS SUPERIOR;

ITS CADSATION, CLINICAL CODRSE AND TERMINATION, WITH A REPORT OF SIX CASES.*

WARD A. HOLDEN, M.D., AND JOSEPH COLLINS, M.D. NEW YORK.

Iuflammation of the gray matter, the parenchyma, as it were, of the central nervous system constitutes the anatomical basis of some of the most sharply defined clinical pictures that physicians encounter. For instance, when it involves the anterior horns of the spinal cord the symptoms that result are few and are very easily interpreted. The same may be said of the symptoms that follow involvement of the gray matter of the oblongata, although the clinical picture may not be so simple because of the great variety of functional endowment which this small part of the central nervous system has.

Many of the diseases dependent on inflammation or other acute pathologic process in the gray matter of the central nervous system have had a suitable place in medical literature for a very long time. Others, such as acute hemorrhagic encephalitis, are recent additions, and much still remains to be learned concerning their causation, course and termination. The disease to which we desire to make a contribution, viz., that known as polioencephalitis superior (inferior ophthalmoplegia, or superior bulbar paralysis,) has been recognized only during the past twenty-five years, having been first described by Wernicke in 1881 . He based the description and the successful endeavor to establish the disease as a clinical entity on three cases in which, after death, a termination quickly reached, acute hemorrhagic and inflammatory destruction was found in the gray matter around the third ventricle. The symptoms which these patients presented were chiefly ocular palsies, staggering gait, optic neuritis and an associated delirium, with agitation resembling that of delirium tremens. As each one of the patients was alcoholic, Wernicke stated that alcoholism was the most potent factor in the cause of the disease, but he did not attempt to maintain that it was the only cause. He was also impressed with the rapidity with which the disease pursued its course and reached a fatal termination.

In consequence of Wernicke's teaching the dependence of the disease on alcoholic intoxication and its fatal termination were generally accepted by the profession. That the disease might occur in two or three stages was demonstrated by the cases recorded by Uhthoff, Salomonsohn, Wolfe and others, while the cases reported by Thompson, Werner, Boedecker and Herrnheiser showed that it is not necessarily fatal.

It is now generally believed that the morbid condition constituting the anatomic basis of the disease is not unlike that constituting the pathologic process in various other inflammations of the gray matter throughout the central nervous system. In other words, the anatomic basis of acute, hemorrhagic, non-purulent encephalitis may be practically similar to that of acute superior polioencephalitis, and that the different course and termination of the latter is conditioned particularly by the location of the disease and by the proximity of important structures which may become secondarily disordered, as well as by structural changes in remote parts of the body, brought about by the protracted indulgence in the use of the substance which was the most potent

* A preliminary report on some of these cases was read before the American Ophthalmological Society, June, 1906. 